Note: This is a pre-copy-editing, author-produced PDF of an article accepted for publication in Epidemiology and Infection following peer review. The definitive publisher-authenticated version [Barry J and Mullen L (2001) An analysis of 15-19-year-old first attenders at the Dublin Needle Exchange, 1990-97, Addiction (2001) 96, 251-258] is available online at

http://www3.interscience. wiley.com/journal/120188476/abstract

\title{
An analysis of 15-19-year-old first attenders at the Dublin Needle Exchange, 1990-97
}

\author{
LOUISE MULLEN \& JOSEPH BARRY
}

Published in Addiction (2001) 96(2), 251-258

\begin{abstract}
Aims: Identification of characteristics and trends over time in young injecting drug users at first attendance at needle exchange. Design: Retrospective cross-sectional survey of routinely collected data. Setting: Dublin needle exchange programme which consists of 11 sites in the greater Dublin area. Participants: First-time attenders $(n=1224)$ at the needle exchange from 1990 to 1997, between the ages of 15 and 19. Measurement: Factors associated with a likelihood of needle sharing and condom use were tested using logistic regression. Findings: Increases in both the number and proportion of young injectors, particularly young female injectors, have occurred over the 8 years. Forty-eight per cent of the young injectors were injecting for less than 1 year. Needle sharing prevalence in the year previous to first attendance was 39\% and condom use was $61 \%$. The proportion of females not using a condom during sexual relationships was significantly higher than males. Very few of the young attenders had received any treatment for drug dependence.

Conclusions: After the first year of injecting drug use the likelihood of needle sharing increased and we recommend that interventions occur early on and are targeted to the needs of young injecting drug users, in particular young females. It is essential that services are accessible to the young injecting drug user and that barriers to contact with services are minimized or eliminated. Some highrisk behaviours are occurring in the context of the sexual relationship and this should be taken into account when designing prevention programmes, especially for young females.
\end{abstract}

\section{Introduction}

The total number of injecting drug users in Ireland is unknown, but is estimated to be at least 13000 14000 in the greater Dublin area. ${ }^{1}$ In Ireland, 98\% of heroin misusers in treatment are resident in the Eastern Health Board (EHB) region. ${ }^{2}$ The EHB is responsible for health services in Dublin City and county and counties Kildare and Wicklow, population 1245225 (1991 census). Dublin is the centre for opiate use in Ireland and there is little evidence of injecting drug use outside this region.2

The 1997 Annual Report of the European Monitoring Centre for Drugs and Drug Addiction (EMCDDA) indicates that Ireland has the youngest mean age of treated drug use in Europe at 23.6 years and two-thirds of treated drug users are under the age of 25 years. ${ }^{3}$ The treated drug user statistics do not include data from needle exchange, which is not designated a treatment service.

In 1989 the first needle exchange was established by the EHB in an inner city location. The number of exchanges has grown steadily to meet demand for increased and localized services. Services have expanded from city centre locations to servicing needs in satellite clinics in suburban areas. A mobile clinic has also been established, bringing the total number of clinics to 11 . Injecting drug users are at high risk for infection with the human immunodeficiency virus (HIV) ${ }^{4}$ and hepatitis. ${ }^{5,6}$ The estimated rate of HIV in the European Union adult population aged 1559 years is 198 cases per $100000,42 \%$ of cases being injecting drug use-related. ${ }^{4}$ Needle exchange programmes are designed to meet the needs of drug users who are unwilling or unable to cease injecting. The clients of needle exchange have been largely male, older and longer-term injectors. ${ }^{7,8}$ The aim of needle exchange is to reduce the transmission of blood-borne infection. 
${ }^{9}$ The Dublin needle exchange programme encourages a reduction or cessation in the sharing of injecting equipment and unsafe sexual practices. The exchanges supply sterile injecting equipment and safe injecting instruction. Contact with outreach workers for education, counselling and referral to treatment services is also provided. The needle exchanges are made as accessible as possible with no or low thresholds for eligibility. This includes a walk-in service, no waiting list, minimal identification requirements and informal relationships with staff. The contact and building of relationships with trained staff provides a potentially important channel to other services.

Needle exchanges are largely funded and staffed by the health board but are separate from treatment and rehabilitation addiction services. This facilitates a low threshold and easy access to the service. One large city-centre needle exchange is administered by a voluntary agency but reports data to the EHB database. The locations are varied and include health centres, clinics and community hospitals. The exchanges do not supply methadone maintenance treatment.

There are few studies specifically concerned with young injectors. A Dutch cohort study found that a number of young users (under 25 years of age) had short injecting histories and had a lower seroprevalence of HIV than the whole cohort. ${ }^{10}$ Young injectors and particularly recent onset injectors were found to be at greater risk of HIV infection than the older and longer-term users due at least in part to behavioural factors. In another study, newly initiated injectors were at particular risk of seroconversion compared to the group as a whole because of an increased level of sharing of injecting equipment. ${ }^{11} \mathrm{~A}$ recent study in Dublin found drug users aged under 25 significantly more likely to report borrowing and lending used injecting equipment compared to older drug users. ${ }^{12}$ The objective of the present study was to establish demographic characteristics, drug-taking characteristics and risk behaviours of first-time attenders at needle exchanges, aged between 15 and 19 years. In addition, trends over time were identified.

\section{Methods}

The study population consisted of 1224 injecting drug users aged 15-19 inclusive attending the Dublin needle exchange programme for the first time between 1990 and 1997 inclusive. The data are a subset $(21 \%, 1224 / 5778)$ of a larger database of the Dublin needle exchange. Data from the whole sample are presented throughout the paper for comparison purposes. The first needle exchange site in Dublin was established mid-year in 1989 and data from this year were excluded.

All data on first attendance for the years 1990- 97 inclusive were used in the analysis. The database was established at the initiation of the needle exchange programme. All needle exchange programme sites participate in the system. Specially trained outreach workers run the needle exchanges.

Outreach workers collect the data in a face-to-face interview with the drug user at first presentation and at each subsequent visit. Data are collected on all attendees, who are asked only for their first and last initials and their date of birth. Names are not requested but initials and date of birth are collected in order to prevent duplication of data due to multiple presentation. During the first attendance, detailed data are recorded on a standard ' $4 \times 6$ ' card. A unique number is assigned at a central location where data from all the clinics are coded by a designated clerical officer and entered into the Health Board's mainframe computer. The database is checked for duplications.

\section{Data form content}

At first attendance the following data are recorded.

- Socio-demographics: initials, sex, date of birth, date of visit, area of residence.

- Drug injecting and other characteristics: number of years of injecting drug use, primary drug of use, reported hepatitis and/or jaundice since initiation of injecting, number of detoxifications received, currently attending methadone maintenance treatment, interest in receiving methadone treatment, year of last HIV test and condoms taken at visit.

- Risk behaviours: needle sharing, number of sexual partners and condom use

The risk behaviour questions asked were: 'Have you shared needles in the previous year?' 'How many sexual partners have you had in the previous year?' and 'Have you used condoms during sexual encounters in the previous year?' No further details on these variables were elicited. The data 
form was designed to be filled out quickly and provide simple comparable quantitative data between the clinics and over time. The risk behaviour questions were designed to be answered in an 'always/sometimes/never' format, but were also in practice answered in a 'yes/no' format.

Therefore responses were recoded so that for the variable 'needle sharing' responses 'always', 'sometimes' and 'yes' were coded as positive responses and 'never' was coded as a negative response. For the variable 'condoms use' responses 'always' and 'yes' were coded as positive responses and 'sometimes' and 'never' were coded as a negative response.

\section{Data analysis}

Data were downloaded from the mainframe health board computer and analysed using the SAS institute Jump In $^{\circledR}$ programme and Epi-Info 6. Data were screened, and recoding and reconciling of codes took place at this time. Frequency distributions were completed for all nominal variables and means, medians and ranges were computed for continuous variables.

To test association between variables, Pearson's chi-square tests and Fisher's exact test were used for univariate comparisons. For assessing trend, chi-square tests for trend were used. Continuous variables-age, number of years injecting and number of sexual partners-did not have normal distributions and were recoded to categorical variables after means, medians and ranges were obtained.

Factors associated with a likelihood of needle sharing and condom use were tested using logistic regression. Logistic regression was undertaken and two models were run with one looking at needle sharing and the other at condom use. Not using a condom was used as the dependent variable as the lack of condom use indicates the presence of risk. Variables were prepared for logistic regression analysis by transformation to binomial categories or dummy variables were created. Variables for logistic regression were initially entered independently and odds ratios with $95 \%$ confidence intervals were computed. Variables were then grouped into socio-demographic, drug behaviour and risk behaviour categories and run separately through a multiple logistic regression. Variables that were statistically significant and variables thought to be relevant and important were retained. A final model was fitted using these variables and different combinations were tried resulting in a final model. Interactions were tested for in the final model.

\section{Results}

Demographics of young injectors

The overall trend in the number of young injecting drug users attending the Dublin needle exchange programme increased between 1990 and 1997 (Table 1). Data from the whole sample are presented in the table for comparison purposes. There was a significant increase in the proportion of young injectors when analysing the whole sample, $X^{2} \operatorname{tr}=215.87, p=<0.0001$.

There was also a significant increase in the proportion of females in the young age group, $X^{2} \operatorname{tr}=$ $19.40, p=<0.0001$. The total number of attenders aged 15-19 was 1224 . Due to missing data or unusable data this denominator changes with different variables. The mean age of attenders in the 15-19 age group was 18.59 (SD5 0.99), median age 18. The mean age of attenders in the whole sample of needle exchange attenders was 25.0 (SD5 5.8), median age 23, range 15-58. 
Table 1. Number and gender of attenders age 15 to 19 and overall numbers of needle exchange attenders, 1990-1997

\begin{tabular}{llclcll}
\hline Year of attendance & $N$ & $\begin{array}{c}\text { Male } \\
\%\end{array}$ & $N$ & $\begin{array}{c}\text { Female } \\
\%\end{array}$ & $\begin{array}{l}\text { No. of 15-19/ no. in } \\
\text { whole sample }\end{array}$ & Proportion \% \\
\hline 1990 & 38 & 86 & 6 & 14 & $44 / 345$ & 13 \\
1991 & 15 & 94 & 1 & 6 & $16 / 228$ & 7 \\
1992 & 58 & 88 & 8 & 12 & $66 / 587$ & 11 \\
1993 & 119 & 74 & 41 & 26 & $160 / 904$ & 22 \\
1994 & 164 & 80 & 42 & 20 & $206 / 948$ & 23 \\
1995 & 216 & 79 & 59 & 21 & $275 / 1217$ & 31 \\
1996 & 138 & 68 & 65 & 32 & $203 / 652$ & 27 \\
1997 & 169 & 68 & 80 & 32 & $249 / 910$ & 21 \\
Total & 917 & & 302 & & $1219 / 5791$ & \\
\hline
\end{tabular}

Number of years injecting

Forty-eight per cent (584/1212) of the young injectors had been injecting for less than 1 year and $98 \%$ $(1188 / 1212)$ had been injecting for less than 5 years. This compared with $29 \%(1686 / 5728)$ of the whole sample, with an injecting duration of under 1 year and $69 \%(3974 / 5728)$ under 5 years.

Specific durations of less than 1 year (days/weeks/months) were not recorded.

The primary drug of use was heroin $853 / 1006$ (85\%). During the early 1990 s there was a proliferation of morphine sulphate tablets in Dublin and this largely accounts for the other $15 \%$.

\section{Treatment and exchange services}

Methadone treatment services were not provided at the exchanges but referral to treatment services was facilitated. Eight per cent (79/1010) of young injectors reported that they were currently receiving methadone treatment from treatment services, which are separate from needle exchange services. Interest in receiving methadone treatment was high at $76 \%$ (779/1022). Very few of the young attenders had received any treatment; 73\% (871/1192) had never attended a detoxification programme. Twenty-three per cent (283/1224) of young injectors reported having had an HIV test. The interval between the HIV test and first attendance at needle exchange is 1 year or less for $89 \%$ (250/282) of cases. Information on results of HIV test is unknown.

\section{Number of sexual partners}

The number of sexual partners in the previous year for young injectors is shown in Table 2. The mean number of sexual partners in the previous year was 3.06, median was 2 and inter-quartile range (IQR) was $1-3$. There was a range of 1-40 partners. This compared to the whole sample in which the mean number of sexual partners in the previous year was 2.55 , median was 1.0 and IQR $1-3$. There was a range of 1-100 partners. The means exclude people who had no sexual partners in the previous year.

Table 2. Number of sexual partners of young injectors in the previous year

\begin{tabular}{lcccccc}
\hline & \multicolumn{2}{c}{ Male } & \multicolumn{2}{c}{ Female } & \multicolumn{2}{c}{ Total } \\
\cline { 2 - 7 } No. of sexual partners & $\mathrm{N}$ & $\%$ & $\mathrm{~N}$ & $\%$ & $\mathrm{~N}$ & $\%$ \\
\hline None & 144 & 16 & 55 & 19 & 199 & 17 \\
One & 321 & 36 & 172 & 58 & 493 & 41 \\
More than one & 428 & 48 & 70 & 24 & 498 & 42 \\
Totals & 893 & & 297 & & 1190 & \\
\hline
\end{tabular}

$x^{2}=58.32, p=<0.0001$ 
Table 3. Trends in needle sharing and condom use for attenders age 15-19

\begin{tabular}{|c|c|c|c|c|c|c|c|c|}
\hline \multirow[b]{3}{*}{ Year } & \multicolumn{4}{|c|}{ Needle sharing } & \multicolumn{4}{|c|}{ Condom use } \\
\hline & \multicolumn{2}{|c|}{$15-19$} & \multicolumn{2}{|c|}{ All attenders } & \multicolumn{2}{|c|}{$15-19$} & \multicolumn{2}{|c|}{ All attenders } \\
\hline & $\mathrm{N}$ & $\%$ & $\mathrm{~N}$ & $\%$ & $\mathrm{~N}$ & $\%$ & $\mathrm{~N}$ & $\%$ \\
\hline 1990 & 15 & 47 & 106 & 43 & 7 & 54 & 48 & 53 \\
\hline 1991 & 4 & 33 & 83 & 40 & 4 & 57 & 53 & 43 \\
\hline 1992 & 31 & 50 & 281 & 51 & 31 & 59 & 260 & 53 \\
\hline 1993 & 62 & 40 & 371 & 44 & 93 & 55 & 391 & 52 \\
\hline 1994 & 64 & 37 & 287 & 37 & 95 & 57 & 379 & 52 \\
\hline 1995 & 79 & 34 & 379 & 36 & 146 & 65 & 543 & 57 \\
\hline 1996 & 65 & 34 & 181 & 31 & 111 & 62 & 291 & 55 \\
\hline 1997 & 104 & 45 & 332 & 40 & 139 & 66 & 474 & 63 \\
\hline Total & 424 & 39 & 2020 & 39 & 626 & 61 & 2439 & 55 \\
\hline
\end{tabular}

\section{Gender}

The proportion of 15-19-year-old females not using a condom during sexual relationships was significantly higher than males $48 \%(130 / 271)$ vs. $36 \%(304 / 839), X^{2}=11.85, p=0.0007$. This is similar to the whole sample in which significantly more females reported not using a condom during sexual relationships in the previous year than males, $51 \%(524 / 1027)$ vs. $44 \%(1804 / 4125), X^{2}=$ 17.64, $p=<0.0001$ )

Females had a higher prevalence of needle sharing than males, but this result was not statistically significant, $42 \%(113 / 267)$ vs. $38 \%(310 / 814), X^{2}=1.5, p=0.22$. This compares with the whole sample in which significantly more females reported needle sharing in the previous year than males, $44 \%(448 / 1012)$ vs. $\left.38 \%(1568 / 4117), X^{2}=13.02, p=0.0003\right)$.

\section{Needle sharing}

Young injectors had a 39\% (424/1087) needle sharing prevalence in the previous year, no different than the whole sample $39 \%(2020 / 5129), X^{2}=0.05, p=0.83$. Needle sharing prevalence fluctuated from year to year with no significant decreasing trend over time in the young group $\left(X^{2} \operatorname{tr}=0.17, p=\right.$ $0.68)$, and a significant decreasing trend in the older group $\left(X^{2} \operatorname{tr}=0.24 .8, p=<0.0001\right)$ (Table 3 ). Recent injectors, and those who use condoms, are less likely to share needles. Needle sharing is more likely in injectors with more than one sexual partner and those reporting hepatitis or jaundice (Table 4).

Table 4. Characteristics associated with needle sharing in injecting drug users age 15-19 at first attendance

\begin{tabular}{|c|c|c|c|c|c|}
\hline - & $\mathrm{N}(\%)$ & Crude OR & $95 \% \mathrm{Cl}$ & Adjusted OR & $95 \% \mathrm{Cl}$ \\
\hline \multicolumn{6}{|l|}{ Sex } \\
\hline Female & $302(25)$ & 1 & & & \\
\hline Male & $917(75)$ & 0.82 & $0.62-1.09$ & & \\
\hline \multicolumn{6}{|c|}{ Injecting duration } \\
\hline$\geq 1$ year & $628(52)$ & 1 & & 1 & \\
\hline$<1$ year & $584(48)$ & 0.69 & $0.54-0.88$ & 0.70 & $0.51-0.95$ \\
\hline \multicolumn{6}{|c|}{$\begin{array}{l}\text { Condom use in the } \\
\text { previous years }\end{array}$} \\
\hline No & $434(39)$ & 1 & & 1 & \\
\hline Yes & $676(61)$ & 0.50 & $0.38-0.65$ & 0.48 & $0.35-0.65$ \\
\hline \multicolumn{6}{|c|}{$\begin{array}{l}\text { Sexual partners in } \\
\text { previous year }\end{array}$} \\
\hline None & 199 (17) & & & & \\
\hline One & $493(41)$ & 1 & & 1 & \\
\hline > One & $498(42)$ & 1.34 & $1.03-1.75$ & 1.47 & $1.08-1.99$ \\
\hline \multicolumn{6}{|c|}{$\begin{array}{l}\text { Self-report of } \\
\text { hepatitis/jaundice }\end{array}$} \\
\hline No & $801(87)$ & 1 & & 1 & \\
\hline Yes & $115(13)$ & 2.06 & $1.38-3.08$ & 1.75 & $1.12-2.72$ \\
\hline
\end{tabular}

776 observations for multivariate analysis. 
Table 5. Characteristics associated with lack of condom use in injecting drug users age 15-19 at first attendance

\begin{tabular}{|c|c|c|c|c|c|}
\hline & $\mathrm{N}(\%)$ & COR & $95 \% \mathrm{Cl}$ & AOR & $95 \% \mathrm{Cl}$ \\
\hline \multicolumn{6}{|l|}{ Sex } \\
\hline Female & $302(25)$ & 1 & & & \\
\hline Male & $917(75)$ & 0.59 & $0.44-0.79$ & & \\
\hline \multicolumn{6}{|c|}{ Injecting duration } \\
\hline$\geq 1$ year & $628(52)$ & 1 & & & \\
\hline$<1$ year & $584(48)$ & 0.93 & $0.73-1.18$ & & \\
\hline \multicolumn{6}{|c|}{$\begin{array}{l}\text { Needle sharing in } \\
\text { previous year }\end{array}$} \\
\hline No & $658(61)$ & 1 & & 1 & \\
\hline Yes & $423(39)$ & 2.00 & $1.53-2.63$ & 2.31 & $1.70-3.16$ \\
\hline \multicolumn{6}{|c|}{$\begin{array}{l}\text { Sexual partners in } \\
\text { previous year }\end{array}$} \\
\hline None & $199(17)$ & & & & \\
\hline One & $493(41)$ & 1 & & 1 & \\
\hline$>$ One & $498(42)$ & 0.57 & $0.44-0.74$ & 0.55 & $0.41-0.75$ \\
\hline \multicolumn{6}{|c|}{ Condoms taken at visit } \\
\hline No & $362(43)$ & 1 & & 1 & \\
\hline Yes & $471(57)$ & 0.43 & $0.33-0.56$ & 0.33 & $0.25-0.45$ \\
\hline
\end{tabular}

796 observations for multivariate analysis.

\section{Condom usage}

Excluding those that did not have a sexual partner in the previous year, 61\% (676/1110) reported condom usage. Young injectors' condom use was significantly higher than the overall population $\left(61 \%(601 / 980)\right.$ vs. $\left.53 \%(1822 / 3418), X^{2}=19.8, p=<0.0001\right)$. Condom use increased significantly over the 8 years in the young injectors $\left(X^{2} \operatorname{tr}=5.21, p=0.02\right)$ and in the overall group $\left(X^{2} \operatorname{tr}=22.4, p=<\right.$ 0.0001 ) (Table 3). Young injectors with more than one sexual partner in the previous year were more likely to use condoms during sex than injectors with one partner $\left(68 \%, 334 / 493\right.$ vs. $55 \%, 267 / 487, X^{2}$ $=17.25, \mathrm{p}=<0.0001$ ).

The logistic regression analysis is shown in Table 5. The study found that the characteristic most associated with lack of condom use in the previous year was needle sharing. Male injectors were more likely to use condoms. Injectors with more than one sexual partner and those that took condoms at the visit were also more likely to use condoms.

\section{Discussion}

We have found evidence that both the number and proportion of young injectors has increased significantly over the 8 years of the needle exchange programme. This study provides a quantitative data analysis of Dublin's needle exchange database. Characteristics of injectors aged 15-19 are described and prevalence of risk behaviours and trends over time at first attendance were identified. A limitation of this study is that, as it is based on an analysis of a routine data source, some explanatory details on drug taking and risk behaviour are absent. Therefore, we are unable to provide data on lending and borrowing, or details of sexual partners. Because the study is essentially a series of cross-sectional studies and not a cohort study there is a potential danger of over interpretation. The data consist of self reported measures from drug users and there is no objective confirmation of the validity of answers. However, findings in other studies support the use of retrospective self reports and have found self-reported drug use and risk behaviour of injecting drug users reliable. ${ }^{13,14}$

In other countries, needle exchange attendance is generally associated with older injecting drug users and injectors with long injecting careers but in this study young injectors presented at the needle exchange in increasingly large numbers. These young injectors had recent onset of injecting, and half had been injecting less than 1 year. Risk behaviour was evident with many reporting needle sharing in the previous year. Needle exchange was the first contact with services for many as few had received treatment. 
In this study, needle sharing prevalence was the same in the younger age group as the overall group of attenders at needle exchange. This could be due to the young age of the overall group. We have found that needle sharing was more likely in drug users who had been injecting one year or more. Needle sharing was associated with having more than one sexual partner and was less likely when condom use was reported. This requires more qualitative analysis to interpret the complex relationship between injecting and sexual risk behaviours.

There was a trend of increased use of condoms over the study period. Eighty-four per cent of young injectors had been sexually active in the year previous to their first attendance at needle exchange. Condom use was more likely in the 15-19 age group compared to the overall group of attenders. In 1993 there was a change in the law in Ireland, making condoms more readily available, although clearly they were available before this time. Injectors with multiple sexual partners appear to be protecting themselves by using condoms compared to those with one sexual partner. Females had a significantly lower prevalence of condom use compared to males.

Almost two-thirds of females in this study reported having had only one sexual partner in the previous year. Other studies found women injectors are often in relationships with injecting men and are less likely to use condoms. ${ }^{15}$ The sexual relationship as the context for risk behaviour is important to consider in prevention programmes. Where risks are being taken as part of a sexual partnership targeting the couple for intervention must be considered. ${ }^{16}$

The potential for intervention and prevention in this young cohort has important public health implications. Prevention measures may not have initially been envisioned to be needed by such a young population and may not be targeted enough. Young injectors' early appearance at needle exchange may indicate an awareness of the risks of sharing needles and a concern to protect themselves. The number of recent onset injectors presents an opportunity for intervention and health service provision and. emphasizes the importance of early preventive interventions. Every effort must be made to ensure that services are accessible and effective so that young people are encouraged to embrace the wider services that are available to them and that they are protected from infection and the social disintegration that can occur with prolonged drug misuse. The progress of individuals from services such as needle exchange to treatment services should be strengthened without compromising the low threshold accessibility and acceptability of the needle exchanges. It is important that young people do not encounter barriers to service from policies, such as parental permission or mandatory treatment.

The information gained from this analysis of the needle exchange programme can be used to identify groups within the drug injecting community that may need prevention and service programmes targeted to their needs. Young injectors have specific needs that can be met by a service willing to address them. Attention should be paid to young female injectors who may need services that take into account their patterns of behaviour and the presence of sexual partners in their lives.

Qualitative research in this population will help fill in the gaps of understanding and knowledge with regard to this drug injecting group. Injecting drug users in Dublin come largely from marginalized areas of the city where poor socioeconomic conditions are the norm. Prevention initiatives will be greatly enhanced by a better understanding of the issues surrounding drug use, risk management and sexual relationships. Of equal importance are social initiatives to address the causes of the problem, including tackling social deprivation and marginalization.

\section{Acknowledgements}

The authors would like to acknowledge the assistance of the following: the Department of Community Health and General Practice, Trinity College Dublin and the Eastern Health Board. This research was completed as part of a MSc in Community Health at Trinity College. 


\section{References}

1. EUROPEANMONITORING CENTRE FOR DRUGS AND DRUG ADDICTION (EMCDDA) (1997) Methodological Pilot Study of Local Prevalence Estimation (Lisbon, EMCDDA).

2. MORAN, R., O'BRIEN, M. \& DUFF, P. (1996) Treated Drug Misuse in Ireland (Dublin, Health Research Board).

3. EUROPEANMONITORING CENTRE FOR DRUGS AND DRUG ADDICTION (EMCDDA) (1997) Annual Report on the State of the Drugs Problem in the European Union (Lisbon, EMCDDA).

4. BROWN, P. J. (1998) Human immunodeficiency virus risk behaviours and their management in drug misusers, Current Opinion in Psychiatry, 11, 265-271.

5. VAN BEEK, I., DWYER, R., DORE, G. J., LUO, K. \& KALDOR, J. M. (1998) Infection with HIV and hepatitis $C$ virus among injecting drug users in a prevention setting: retrospective cohort study, British Medical Journal, 317, 433-437.

6. LEVINE, O. S., VLAHOV, D. \& NELSON, K. E. (1994) Epidemiology of hepatitis B virus infections among injecting drug users: seroprevalence, risk factors, and viral infections, Epidemiological Review, 16, 418-436.

7. DONOGHOE, M. C., STIMSON, G. V. \& DOLAN, K. A. (1992) Syringe Exchange in England (London, Tufnell Press).

8. KORF, D. J. (1995) Dutch Treat (Amsterdam, Thesis Publishers).

9. DURANTE, A. J., HART, G. J., BRADY, A. R., MADDEN, P. B. \& NOONE, A. (1995) The Health of the Nation target on syringe sharing: a role for routine surveillance in assessing progress and targeting interventions, Addiction, 90, 1389-1396.

10. FENNEMA, J. S., VAN AMEIJDEN, E. J. C., VAN DEN HOEK, A. \& COUTINHO, R. A. (1997) Young and recent-onset injecting drug users are at higher risk for HIV, Addiction, 92, 1457-1465.

11. RHODES, T. J., HUNTER, G. M., STIMSON, G. V., DONOGHUE, M. C., NOBLE, A., PARRY, J. \& CHALMERS, C. (1996) Prevalence of markers for hepatitis B and HIV-1 among drug injectors in London: injecting careers, positivity and risk behaviour, Addiction, 91, 1457-1467.

12. CASSIN, S., GEOGHEGAN, T. \& COX, G. (1998) Young injectors: a comparative analysis of risk behaviour, Irish Journal of Medical Science, 167, 234-237.

13. DE IRALA, J., BIGELOW, C., MCCUSKER, J., HINDIN, R. \& LI, Z. (1996) Reliability of selfreported human immunodeficiency virus risk behaviours in a residential drug treatment population, American Journal of Epidemiology, 143, 725-732.

14. MCELRATH, K., CHITWOOD, D., GRIFFIN, D. \& COMERFORD, M. (1994) The consistency of self-reported HIV risk behaviour among injection drug users, American Journal of Public Health, 84, 1965-1970.

15. BARNARD, M. A. (1993) Needle sharing in context: patterns of sharing among men and women injectors and HIV risks, Addiction, 88, 805-812.

16. RHODES, T. \& QUIRK, A. (1998) Drug users' sexual relationships and the social organisation of risk: the sexual relationship as a site of risk management, Social Science and Medicine, 46, 157169. 